\title{
Enteric bacteria, methicillin resistant S. aureus and antimicrobial susceptibility patterns from buses surfaces in Mekelle city, Tigray, Ethiopia
}

\author{
Atsebaha Gebrekidan Kahsay ${ }^{*}$, Solomon Weldegebreal Asgedom² ${ }^{2}$ and Haftom Legesse Weldetinsaa ${ }^{3}$
}

\begin{abstract}
Objective: To assess the enteric bacteria, methicillin resistant $S$. aureus and antimicrobial susceptibility patterns from buses surfaces in Mekelle, Tigray, Ethiopia.

Results: A total of 300 swab samples were collected from the handle surfaces of the six city buses. The bacterial isolates revealed from the swab samples were E. coli, Enterobacter spp. and S. aureus. The overall positivity rates of E. coli, Enterobacter spp. and S. aureus were 8 (4\%), 4 (1.3\%) and 54 (18\%) respectively. Methicillin resistant S. aureus was seen in 17 (5.7\%) of the total 300 swab samples collected and 17 (31.5\%) of the S. aureus isolates. All (100\%) of the isolates of E. coli and Enterobacter spp. showed resistance for ampicillin and three-fourth of the isolates of E. coli and Enterobacter spp. displayed resistance for chloramphenicol (75\%). Five antimicrobials (ampicillin, chloramphenicol, tetracycline, ciprofloxacin, and cotrimoxazole) have showed resistant for one isolate of E. coli. Likewise four antimicrobials (ampicillin, chloramphenicol, ciprofloxacin, and cotrimoxazole) have revealed resistant for one isolate of Enterobacter spp. Moreover, three isolates of $S$. aureus were also found resistance to four antibiotics.
\end{abstract}

Keywords: Enteric bacterial, Escherichia coli, Staphylococcus aureus, Antimicrobial susceptibility test, Mekelle, Bus

\section{Introduction}

Transportation network systems are important to transport passengers from one area to the other area. With the expansion of transportation network systems, parallel expansions of communicable diseases in the globe are fashionable from time to time [1]. These transportation networks leave people at risk from the emergence of new strains of diseases in the globe [2]. This would be the worst if the pathogenic microorganisms developed drug resistance. Many studies were conducted all over the world to isolate pathogenic microorganisms from the different surface like public hand touch surfaces of the bus, train, mobile phone, hand knob, hospital, shopping cart

\footnotetext{
*Correspondence: atseba_mu@yahoo.com

${ }^{1}$ Department of Medical Microbiology and Immunology, School of Medicine, College of Health Sciences, Mekelle University, Mekelle, Ethiopia

Full list of author information is available at the end of the article
}

$[3,4]$. Some of the common pathogenic bacteria isolated from hand touch surfaces are E. coli, Salmonella and multi-drug resistant $S$. aureus [5-7].

Escherichia coli are predominately isolated from different surfaces [8] and hand touch surface of public buses. Salmonella typhi and Shigella species are the second and third isolates from hand touch surface of public buses [9]. The transmission of S. aureus is facilitating during crowdedness, significant hand to surface contact and failure to wash hands immediately after dropping from the bus [10]. The infection due to $S$. aureus varies from a simple skin infection to the serious and fatal bacteremia and pneumonia [11]. The contribution of $S$. aureus infection in the surgical site and ventilator-associated pneumonias are $30 \%$ and $24 \%$ respectively [12]. The serious problem of S. aureus is its emergence of drug resistance [13].

This study tried to assess different search engines to find similar published researches in Ethiopia and Africa but unable to find such a research and not included the 
previous overview of enteric bacteria and MRSA in the study area. But, due to the fast growing of the Mekelle city, many young individuals are flowing from the rural area to the city and the city administration is introducing city buses to minimize the shortage of transportation. In line with the transportation, we conducted a research to assess the pathogenic enteric bacteria and MRSA from the handle surfaces of the city buses in the Mekelle city.

\section{Main text}

\section{Materials and methods}

Mekelle, the capital city of Tigray region, is located $784 \mathrm{~km}$ north of Addis Ababa. It is a major economic and educational centre, with a new international airport, federal university teaching hospital and it is the home for Mekelle University. It is also the centre of industrial parks. The city has a huge natural, historic and religious sites and its population growth is increasing from time to time and has an estimated population of 286,600 [14]. It is also an entry point to the Gere Alta landscape and rock-hewn churches and the breathtaking Dallol area in the Afar Region. Due to an increase in the population size in the city, the transportation service becomes an urgent demand.

\section{Study design and period}

The cross-sectional study design was carried out among the city buses surfaces in January and February 2017.

\section{Study subjects and sampling technique}

Six city buses were included in the study. These buses have selected purposively since they are able to transport long distance in the city and able to transport about 100 individuals at a time. Swab samples were taken while the bus completed one trip (at the end of the travel). A single bus has a total of 100 handle surfaces (sit and stand). Swabbing of the handle surfaces was started from the front door by leaving one sit and taking another sit and finally to have 50 swab samples per the single bus. The way of sample collection for all the buses included in this study was similar. Of the total 600 handle surfaces in all the selected city buses, swab samples were collected from the 300 handle surfaces.

\section{Swab sample collection}

A $5 \mathrm{ml}$ sized test tube having $2 \mathrm{ml}$ peptone water with application cotton swab was sterilized at $121{ }^{\circ} \mathrm{C}$ with $15 \mathrm{mmHg}$ for $15 \mathrm{~min}$ in the autoclave [15]. The prepared peptone water broth was put in the ice box while we were going to the swab sample collecting site. The buses were given code numbers from one to six. We designed our protocol to collect 10 swab samples per day excluding Saturday and Sunday. As per the sampling technique, we have recruited 50 samples from Monday to Friday from the bus given the first code number and continued in a similar way to employ a total of 300 swab samples. While we were labeling and collecting the swab samples, we started from the front handle surface near the driver. Once we collected 10 swab samples aseptically from the handle surface, we put in the icebox and transported them into Microbiology laboratory in Mekelle University College of Health Sciences, Department of Medical Microbiology and Immunology.

\section{Isolation and identification of bacteria}

Once arrived in the Microbiology laboratory, the swab samples were inoculated directly into MacConkey agar and Mannitol salt agar and incubated at $37^{\circ} \mathrm{C}$ for $24 \mathrm{~h}$.

After overnight incubation, colonies grown on MacConkey agar were identified and characterized using a series of biochemical tests including oxidase test, urease test, Killer Iron Agar, Indole, Citrate, and also motility test. Although this study hypothesized to assess the enteric bacteria including $E$. coli (may indicate fecal contamination), Shigella and Salmonella but Shigella and Salmonella were not isolated from MacConkey agar. Unfortunately E. coli and Enterobacter spp. were the only bacteria recovered from the swab samples collected.

On the other hand, colonies grown on Mannitol salt agar and having golden yellowish color were identified using gram stain and characterized by biochemical tests including catalase and coagulase tests. Gram-positive in cluster form, catalase positive and coagulase positive colonies were confirmed as S. aureus. Cefoxitin disk was used to identify methicillin-resistant $S$. aureus [16].

\section{Antimicrobial susceptibility tests}

The isolated bacteria were subjected to the antimicrobial susceptibility tests using Kirby Bauer disk diffusion method. Mueller-Hinton agar (HI Media Laboratories, Pvt. Mumbai, India) was used to determine the susceptibility testing. All the antimicrobial disks used were imported from Oxide Ltd. Basingstoke Hampshire England.

The antimicrobial disks used to test bacterial isolates in this study were ampicillin, penicillin, erythromycin, chloramphenicol, ciprofloxacin and cefoxitin, tetracycline and cotrimoxazole. Results were reported as sensitive, intermediate and resistance following clinical laboratory standards institute [16].

\section{Quality control}

During sample collection, we used candle jar to prevent other microorganisms from joining from the air. Each lot and shipment of a medium was checked for expiry date prior to use as part of quality control. The only medium 
which has passed quality control was used for testing. The performance of the media and antimicrobial disks were checked by E. coli strain American Type Culture Collection 25922 (ATCC 25922) and S. aureus (ATCC25923) [16].

\section{Data analysis}

Data were entered and analyzed using SPSS version 20.

Descriptive statistics were calculated into frequencies and percentages and summarized in the table.

\section{Ethical consideration}

Ethical clearance was obtained from the Ethical Review Committee of Mekelle University, College of Health Sciences. Permission was collected from Mekelle city administrative transport office.

\section{Results}

\section{Bacterial isolates}

A total of 300 swab samples were collected from the handle surfaces of the six city buses. The bacterial isolates revealed from the swab samples were E. coli, Enterobacter spp. and $S$. aureus. The overall positivity rates of $E$. coli, Enterobacter spp. and S. aureus were 8 (4\%), 4 (1.3\%) and 54 (18\%) respectively. A cumulative of $66(22 \%)$ bacteria was recovered from the total of 300 swab samples. Methicillin resistant S. aureus was seen in 17 (5.7\% \%) of the total 300 swab samples collected and $17(31.5 \%)$ of the $S$. aureus isolates.

\section{Antimicrobial susceptibility testing}

Bacterial isolates were tested for antimicrobial drugs. These were ampicillin, erythromycin, chloramphenicol, ciprofloxacin, cefoxitin, cotrimoxazole and tetracycline. The resistance patterns of $S$. aureus, E. coli and Enterobacter spp. isolates were explained in Table 1.
Table 2 Multidrug resistant patterns of $E$. coli and Enterobacter spp. among city buses surfaces in Mekelle city, Tigray, Ethiopia, 2017

\begin{tabular}{lllll}
\hline $\begin{array}{l}\text { Antimicrobial } \\
\text { agents }\end{array}$ & $\begin{array}{l}\text { Resistant to } E . \\
\text { coli }\end{array}$ & Isolates & $\begin{array}{l}\text { Resistant } \\
\text { to Enterobacter } \\
\text { spp. }\end{array}$ & Isolates \\
\hline Three & AMP, CAF, TT & 3 & AMP, CAF, COT & 2 \\
Four & AMP, CAF, TT, CIP & 3 & $\begin{array}{l}\text { AMP, CAF, COT, } \\
\text { CIP }\end{array}$ & 1 \\
Five & AMP, CAF, TT, CIP, & 1 & & \\
& COT & & & \\
\hline
\end{tabular}

AMP ampicillin, CAF chloramphenicol, COT cotrimoxazole, $T T$ tetracycline, CIP ciprofloxacin

A single isolate of $E$. coli showed resistance to multiple antimicrobial agents (ampicillin, chloramphenicol, ciprofloxacin, cotrimoxazole and tetracycline) and in a similar way one isolate of Enterobacter spp. displayed resistance to four (ampicillin, chloramphenicol, cotrimoxazole, ciprofloxacin) antimicrobial drugs (Table 2). Three isolates of S. aureus were resistant to four antibiotics "Table 3 “.

\section{Discussion}

With the expansion of transportation network systems, parallel expansions of communicable diseases in the globe are happening from time to time. These transportation networks leave people at risk from the emergence of new strains of diseases in the globe. Some of the common pathogenic bacteria isolated from hand touch surfaces in different studies are E. coli, Salmonella and multi-drug resistant $S$. aureus [5-7]. These are medically important bacteria that anyone can acquire whenever there is poor personal hygiene and this is very common in lowincome countries and leads to diarrhoea $[17,18]$. The problem is not only their acquisition as causative agents

Table 1 Antimicrobial Resistance patterns of S. aureus, E. coli and Enterobacter spp. among city buses surfaces in Mekelle city, Tigray, Ethiopia, 2017

\begin{tabular}{|c|c|c|c|c|c|c|}
\hline \multirow[t]{3}{*}{ Antimicrobial agent } & \multicolumn{2}{|c|}{ S. aureus, $\mathrm{N}=54$} & \multicolumn{2}{|c|}{ E. coli, $\mathrm{N}=8$} & \multicolumn{2}{|c|}{ Enterobacter spp., $\mathrm{N}=4$} \\
\hline & $\mathbf{R}$ & $S$ & $\mathbf{R}$ & $S$ & $\mathbf{R}$ & $\mathrm{S}$ \\
\hline & No (\%) & No (\%) & No (\%) & No (\%) & No (\%) & No (\%) \\
\hline Penicillin & $40(74.1)$ & $14(25.9)$ & - & - & - & - \\
\hline Ampicillin & - & - & $8(100)$ & $0(0)$ & $4(100)$ & $0(0)$ \\
\hline Erythromycin & $6(11.1)$ & $48(88.9)$ & $0(0)$ & $8(100)$ & $0(0)$ & $4(100)$ \\
\hline Chloramphenicol & $37(68.5)$ & $17(31.5)$ & $6(75)$ & $2(25)$ & $3(75)$ & $1(25)$ \\
\hline Ciprofloxacin & $6(11.1)$ & $48(88.9)$ & $3(37.5)$ & $5(62.5)$ & $1(25)$ & $3(75)$ \\
\hline Cefoxitin & $17(31.5)$ & $37(68.5)$ & - & - & - & - \\
\hline Cotrimoxazole & $13(24.1)$ & $41(75.9)$ & $1(12.5)$ & $7(87.5)$ & $2(50)$ & $2(50)$ \\
\hline Tetracycline & $3(5.6)$ & $51(95.4)$ & $6(75)$ & $2(25)$ & $0(0)$ & $4(100)$ \\
\hline
\end{tabular}

$R$ resistant, $S$ susceptible 
Table 3 Multidrug resistant patterns of $S$. aureus among city buses surfaces in Mekelle city, Tigray, Ethiopia, 2017

\begin{tabular}{lll}
\hline $\begin{array}{l}\text { Number } \\
\text { of antimicrobial } \\
\text { resistance }\end{array}$ & S. aureus & Resistance antibiogram \\
\cline { 2 - 3 } Three & $\begin{array}{l}\text { Number } \\
\text { of isolates }\end{array}$ \\
& P, CAF, COT & 1 \\
& P, ERY, CIP & 2 \\
& ERY, CAF, CX & 2 \\
& CAF, CX, TT & 1 \\
& CAF, CX, COT & 1 \\
Four & P, ERY, CAF, CIP & 1 \\
& P, CAF, COT, TT & 1 \\
& CAF, CX, COT, TT & 1 \\
\hline
\end{tabular}

$P$ penicillin, ERY erythromycin, CAF chloramphenicol CEX cefoxitin, COT cotrimoxazole, $T T$ tetracycline, CIP ciprofloxacin, $C X$ cefoxitin

of diarrhea but also their lack of sufficient treatment due to the emergence of drug resistance $[19,20]$. Although this study is unable to identify the most common enteric bacterial pathogens (Shigella and Salmonella), E. coli is an indication that there might be faecal contamination of bus surfaces in the study area. This can be a good opportunity for the spreading of enteric pathogens in the study area. On the other hand, even if it is clear that $S$. aureus is a skin and a nasal flora, its magnitude of infection is from a simple skin infection to a serious infection like pneumonia and septicemia [11, 12]. Moreover, another serious problem of $S$. aureus is its emergence of drug resistance (the emergence of methicillin resistance $S$. aureus) [13]. By its nature, MRSA carrier people may have contact with their nasal secretion by their hand and automatically handle the surface of the bus and as soon as possible another passenger comes and handle the same handle surfaces. This might be a good network for the transmission of MRSA from one to the other.

In the present study, three genuses of bacteria were isolated. These are E. coli, Enterobacter spp. and S. aureus. Similar to the present study E. coli and $S$. aureus were isolated in Bangladesh however unlike to this study Shigella and Salmonella was revealed in Bangladesh [9].

Two-third of the isolates of $S$. aureus were resistance to MRSA. This result is in line with a study conducted in Portugal [10]. Above $18 \%$ of $S$. aureus isolates seems to appear resistant to three and four antimicrobial agents that implies multidrug resistance. One isolate of $E$. coli and Enterobacter spp. showed resistance to five and four antimicrobial drugs respectively. Moreover, three isolates of $S$. aureus were also found resistance to four antibiotics.

\section{Conclusion}

Although the common enteric bacterial pathogens (Shigella and Salmonella) were not revealed from the hand touch surfaces of city buses, the recovery of $E$. coli may indicate the faecal contaminations along the bus surfaces. Multidrug-resistant isolates of $E$. coli were recovered. This study recommends to passengers that they should wash hands before eating to prevent contamination by the enteric bacteria which may induce gastrointestinal diseases. About $5.6 \%$ of the total swab samples and $31.5 \%$ of the S. aureus isolates were resistant to methicillin.

\section{Limitations}

This study lacks the analysis of mecA gene of $S$. aureus which was mandatory to confirm the cefoxitin disc diffusion method.

\section{Abbreviations}

SPSS: statistical software for social sciences; MRSA: methicillin resistance $S$. aureus; CLSI: Clinical Laboratory Standards Institutes; E. coli: Escherichia coli; S. aureus: Staphylococcus aureus.

\section{Acknowledgements}

We would like to thank Mekelle University research and community service office and also my gratitude goes to Mekelle city road and transportation office.

Authors' contributions

AK, SW and HL were participating in designing the proposal, sample collection, experimental work and writing and approving the manuscript. All authors read and approved the final manuscript.

\section{Funding}

Mekelle University (CRPO/CHS/SM/008/09), the funding organization did not have direct participation in design of the study and collection, analysis, and interpretation of data and in writing the manuscript.

\section{Availability of data and materials}

Not applicable.

Ethics approval and consent to participate

The study was ethically approved by the ethical review committee of Mekelle University College of Health Sciences.

Consent for publication

Not applicable.

Competing interests

The authors declare that they have no competing interests.

\section{Author details}

1 Department of Medical Microbiology and Immunology, School of Medicine, College of Health Sciences, Mekelle University, Mekelle, Ethiopia. ${ }^{2}$ School of Pharmacy, College of Health Sciences, Mekelle University, Mekelle, Ethiopia. ${ }^{3}$ Department of Medical Laboratory Sciences, Adigrat University, Adigrat, Ethiopia.

Received: 30 April 2019 Accepted: 5 June 2019

Published online: 13 June 2019 


\section{References}

1. Tatem AJ, Rogers DJ, Hay ST. Global transport networks and infectious disease spread. Adv Parasitol. 2006:62:293-343.

2. Guimera R, Mossa S, Turtschi A, Amaral LAN. The worldwide air transportation network: anomalous centrality, community structure, and cities' global roles. Proc Natl Acad Sci USA. 2005;102:7794-9.

3. Bures S, Fishbain JT, Uyehara CFT, Parker JM, Berg BW. Computer keyboards and faucet handles as reservoirs of nosocomial pathogens in the intensive care unit. Am J Infect Control. 2000;28(6):465-71.

4. Reynolds KA, Watt PM, Boone SA, Gerba CP. Occurrence of bacteria and bacterial markers on public surfaces. Int J Environ Health Res. 2005;15(3):225-34.

5. Gavaldà L, Pequeño S, Soriano A, Dominguez MA. Environmental contamination by multidrug-resistant microorganisms after daily cleaning. Am J Infect Control. 2015;43(7):776-8.

6. Shapiro A, Raman S, Johnson M, Piehl M. Community-acquired MRSA infections in North Carolina children: prevalence, antibiotic sensitivities, and risk factors. N C Med J. 2009;70(2):102-7.

7. Gerba CP, Wuollet AL, Raisanen P, Lopez GU. Bacterial contamination of computer touch screens. Am J Infect Control. 2016:44(3):358-60.

8. Ashgar SS, El-Said HM. Pathogenic bacteria associated with different public environmental sites in mecca city. Open J Med Microbiol. 2012;2:133-7.

9. Chowdhury T, Mahmud A, Barua A, Khalil MDI, Chowdhury R, Ahamed F, Dhar K. Bacterial contamination on hand touch surfaces of public buses in Chittagong city, Bangladesh. J Environ Sci Toxicol Food Technol. 2016;10(4):48-55.

10. Conceic T, Diamantin F, Coelho C, Lancaster H, Aires-de-Sousa M. Contamination of public buses with MRSA in Lisbon, Portugal: a possible transmission route of major MRSA clones within the community. PLoS ONE. 2013:8(11):e77812

11. Murray PR, Rosenthal KS, Pfaller MA. Medical microbiology. 5th ed. Philadelphia: Elsevier Mosby; 2013. p. 332-3.
12. Hidron Al, Edwards JR, Patel J, Horan TC, Sievert DM, Pollock DA, Fridkin SK. Antimicrobial-resistant pathogens associated with healthcareassociated infections: annual summary of data reported to the National Healthcare Safety Network at the Centers for Disease Control and Prevention, 2006-2007. Infect Control Hosp Epidemiol. 2008;29(11):998-1008.

13. Suaya JA, Mera RM, Cassidy A, Hara PO, Amrine-Madsen H, Burstin S, Miller LG. Incidence and cost of hospitalizations associated with Staphylococcus aureus skin and soft tissue infections in the United States from 2001 through 2009. BMC Infect Dis. 2014;14:296.

14. Central statistical agency of Ethiopia, based on population and housing census of 2007, reported in 2013.

15. Cheesbrough M. District laboratory practice in tropical countries part 2. 2nd ed. Cambridge: Cambridge University Press; 2006. p. 90-7.

16. CLSI. Performance standards for antimicrobial susceptibility testing: twenty-second informational supplement, CLIS document, 2012. M100-S22, vol. 32, no. 3. Clinical and Laboratory Institute.

17. Uerrant RL, Oria R, Bushen OY, Patrick PD, Houpt E, Lima AA. Global impact of diarrheal diseases that are sampled by travellers: the rest of the hippopotamus. Clin Infect Dis. 2005;41(Suppl 8):S524-30.

18. Tumwine JK. Clean drinking water for homes in Africa and other less developed countries. BMJ. 2005;331:468-9.

19. Nys S, Okeke IN, Kariuki S, Dinant GJ, Driessen C, Stobberingh EE. Antibiotic resistance of faecal Escherichia coli from healthy volunteers from eight developing countries. J Antimicrob Chemother. 2004;54:952-5.

20. Lamikanra A, Okeke IN. A study of the effect of the urban/rural divide on the incidence of antibiotic resistance in Escherichia coli. Biomed Lett. 1997:55:91-7.

\section{Publisher's Note}

Springer Nature remains neutral with regard to jurisdictional claims in published maps and institutional affiliations.
Ready to submit your research? Choose BMC and benefit from:

- fast, convenient online submission

- thorough peer review by experienced researchers in your field

- rapid publication on acceptance

- support for research data, including large and complex data types

- gold Open Access which fosters wider collaboration and increased citations

- maximum visibility for your research: over $100 \mathrm{M}$ website views per year

At BMC, research is always in progress.

Learn more biomedcentral.com/submissions 